\title{
Resistance to extinction as a function of amount of pretraining in a free-operant situation
}

\author{
KENNETH TRAUPMANN and JOHN J. PORTER, Department of \\ Psychology, The University of Wisconsin-Milwaukee, Wisc. 5320I
}

Two groups of five albino rats were given either no dipper training $(N P)$ or four days of dipper training $(P)$ in a free-operant situation, then all $S$ s were given 25 days of bar-press training. Acquisition was followed by six days of extinction. Results showed both more rapid learning and more rapid extinction of the bar-pressing response by the P-group. However, the extinction results depended on the measure employed.

Ison (1962) and others have demonstrated an overlearning extinction effect in the discrete-trial runway, i.e., extinction proved to be an inverse function of the number of reinforced acquisition trials. Ison \& Cook (1964) and Theios \& Brelsford (1964) have shown that the effect is probably due to the large reward magnitude frequently given in runway studies, smaller rewards tending not to produce the effect.

Theios and Brelsford also showed that this "incentive" effect could be built up by goal-box placements for the reward prior to actual running trials. Goal-box placements of the runway situation could be considered analogous to, say, dipper training in the free-operant situation: both yielding reinforcement without an instrumental response. The following study was carried out to determine if dipper training would lead to decreased resistance to extinction in a fashion similar to the goal-box placement effect. METHOD

Ten female Holtzman rats, 90 days old at the start of the experiment, were tested in a Lehigh Valley rat chamber which was housed in a sound-dampened cabinet. The Ss were first placed on water deprivation for six days to adjust them to $90 \%$ of normal growing body weight. They were maintained on this schedule throughout the study. Five of the Ss (Group P) were then given four days of dipper training at 30 reinforcements per day, delivered on a 20 -sec VI schedule, followed by 25 days of CRF bar-press training at 30 bar presses per day. The other five Ss (Group NP) were given no dipper training, but were also given 25 days of CRF bar-press training starting the same day as the P-group began dipper training. Throughout dipper training and bar-press training a reinforcement for all Ss consisted of 10-sec access to $.20 \mathrm{ml}$ of $20 \%$ sucrose solution. During the $10-\mathrm{sec}$ reinforcement period the house light, which was normally dimmed by a $60-0 h m$ resistor in series with the lamp, was at full intensity. Further, in acquisition responses occurring within the 10-sec reinforcement period failed to re-operate the dipper mechanism and thus were unreinforced and subtracted from S's reservoir of 30 bar presses per day.

Following bar-press training, all Ss were given five days of extinction at 30 bar presses per day, or to a no response criterion of $5 \mathrm{~min}$, whichever came first. This was followed by extinction to the 5-min criterion alone on the sixth day. During extinction, acquisition conditions were maintained except that the dipper remained in its normally-down position, although the light brightened for $10 \mathrm{sec}$ on the same schedule as during training.

\section{RESULTS}

Figure 1 shows the means of the median response times for the first 12 days of bar-press training at which time the difference in bar-press rate between Groups P and NP had stabilized. An analysis of variance over these data showed that the P-group responded faster than the NP-group, $F(1,8)=6.73, p<.05$; an effect of days, $F(3,24)=10.14, p<.001$; and a days by dipper training interaction, $F(3,24)=3.43, p<.05$. The interaction resulted from the significantly slower responding of the NP-group over Blocks 1-3, $F(1,24)=16.77, p<.001$. The groups did not differ at any other block throughout acquisition.

A second analysis of variance was done over the time for the final 10 acquisition trials and the first 10 extinction trials. The

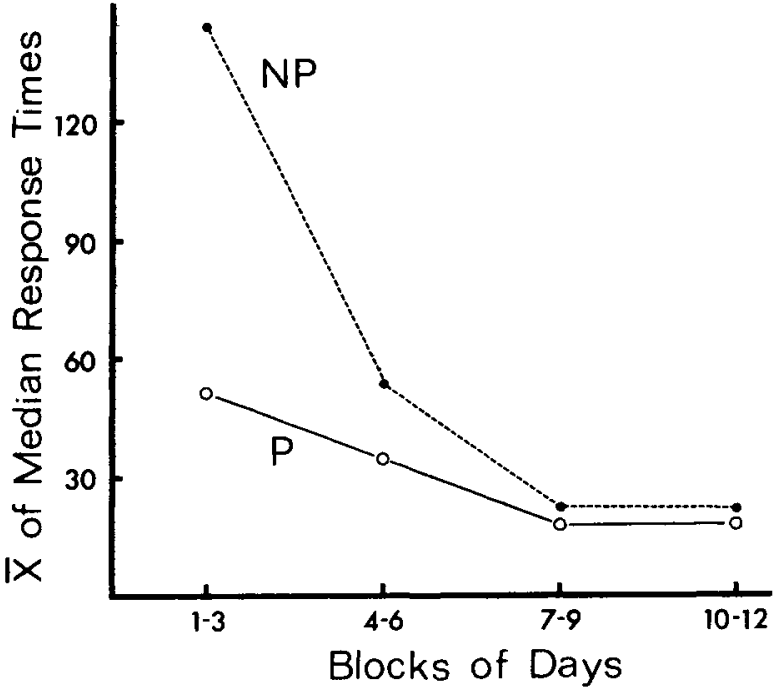

Fig. 1. Mean of median response times over blocks of three days for $P$ - and NP-groups.

only significant effect shown by this analysis was due to pre- vs post-extinction response times, $F(1,8)=15.35, \mathrm{p}<.001 ;$ due to a decrease in response time for both groups (Fig. 2).

Figure 2 also shows the means of the median response times for the last four days of acquisition and the first four days of extinction over two-day periods. An analysis of variance over these data showed no effect of dipper training, $F(1,8)<1.00$; but a significant effect of days, $F(3,24)=4.55, p<.01$; and $a$ significant days by dipper training interaction, $F(3,24)=3.28$, $\mathrm{p}<.05$. This interaction was due to the longer median response times for the P-group over Days 3 and 4 of extinction, $\mathrm{F}(1,24)=8.88, \mathrm{p}<.01$; while the groups failed to differ over the preceding blocks.

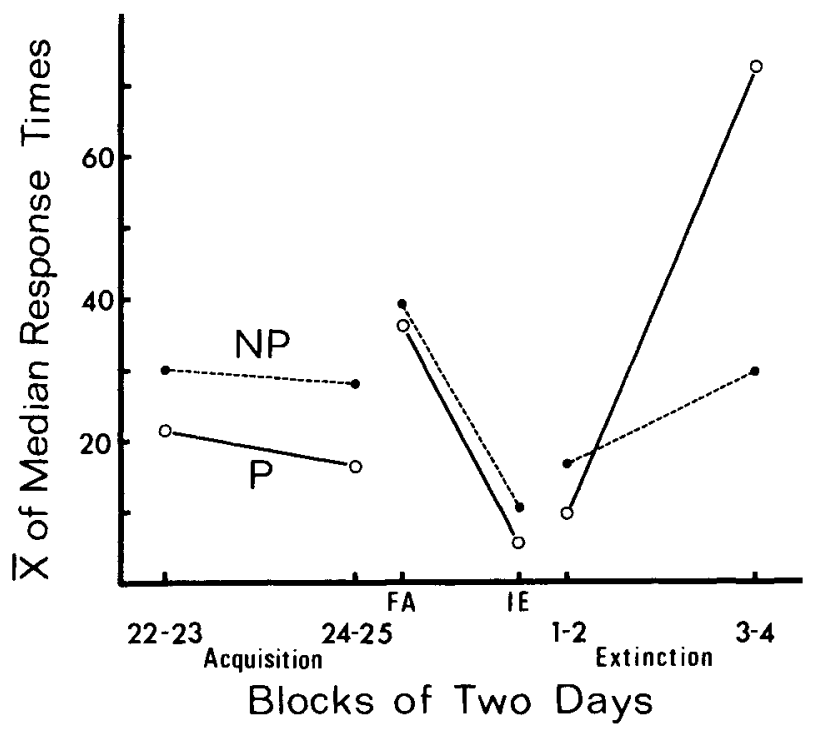

Fig. 2. Mean of median response times over last four days of acquisition and first four days of extinction in blocks of two days, and time for last 10 responses in acquisition (FA) and first 10 responses in extinction (IE) for $P$ and NP-groups. 
A final analysis over the totil time and total number of responses to extinction for the sixth extinction day showed no differences significant at $\mathrm{p} \leqslant .05$ between the $\mathrm{P}$ - and NP-groups for cither measure.

\section{DISCUSSION}

The present study has demonstrated that a bar-pressing response can be learned faster if the $S$ is given pretraining to the reinforcement component of the CRF response than if no such pretraining is given (Fig. 1). It has also been shown that the bar-pressing response tends to extinguish faster when the rat has been pretrained to the dipper (Fig. 2). These data resemble those of an analogous situation where Theios \& Brelsford (1964) demonstrated that rats given reinforced goal-box placements tended to extinguish faster than Ss given the same number of running trials but no prior goal-box placements. Thus, the present study has shown confirmation of the "incentive" effect, i.e., decreased resistance to extinction accompanying increased numbers of reinforcements received at the goal; however, this effect has not been shown to occur within the first 10 extinction responses nor last beyond the first four extinction days. The latter result may have been due to a return to operant level responding by both groups; however, operant levels were not available to test this assumption.

While the "incentive" effect did not appear early in extinction there was a highly significant decrease in response time, or conversely, an increase in response rate, from the final acquisition performance to the initial extinction responding. This effect occurred for both P-and NP-groups and may have simply been due to the Ss of both groups spending more time bar pressing in absence of reward. However, the increase in response rate may also have been the result of frustration occurring with the experience of nonreward (Spence, 1960: Amsel, 1967). It is difficult, however, to evoke frustration as an explanatory device for these data since it would be expected that any differential effect due to frustration would appear early in the extinction process, but the "incentive" phenomenon did not occur until Days 3-4 of extinction. A more tenable explanation might be a discrimination hypothesis, similar to Capaldi's (1967), such that Ss receiving more CRF rewards at the goal are rendered better able to discriminate the extinction from the acquisition stage of training. Thus, extinction should be more readily discriminated from acquisition by the P-group and consequently they should show less resistance to extinction.

\section{REFERENCES}

AMSEL, A. Partial reinforcement effects on vigor and persistance. In K. W. Spence and Janet Taylor Spence (Eds.), The psychology of learning and motivation New York: Academic Press, 1967.

CAPALDI, E. J. A sequential hypothesis of instrumental learning. In K. W. Spence and Janet Taylor Spence (Eds.), The psychology of learning and motivation. New York: Academic Press, 1967.

ISON, J. Experimental extinction as a function of number of reinforcements. Journal of Experimental Psychology, 1962, 64, 314-317.

ISON, J., \& COOK, P. Extinction performance as a function of incentive magnitude and number of acquisition trials. Psychonomic Science, 1964, 1, 245-246.

SPENCE, K. W. Behavior theory and learning. Englewood Cliffs: Prentice Hall, 1960.

THEIOS, J., \& BRELSFORD, J. The overlearning-extinction effect as an incentive phenomenon. Journal of Experimental Psychology, 1964, 67, 463-467. 